\title{
Transformaciones territoriales y estrategias de supervivencia: el caso del municipio de Calpan, Puebla-México 1990-2015
}

\section{Territorial transformations and coping strategies: the case of the municipality of Calpan, Puebla-México 1990-2015}

\author{
José Luis López-González* \\ José Arturo Méndez-Espinoza* \\ Susana Edith Rappo-Miguez** \\ Miguel Ángel Damián-Huato** \\ Jesús Felipe Álvarez-Gaxiola* \\ Juan Alberto Paredes-Sánchez* \\ *Colegio de Postgraduados campus Puebla, Puebla, México \\ **Benemérita Universidad Autónoma de Puebla, Puebla, México \\ Resumen
}

En México, las políticas neoliberales incentivan trasformaciones en los territorios y cambios en las estrategias de supervivencia. Así, el objetivo del estudio fue explicar las transformaciones territoriales en el municipio de Calpan, a partir del análisis de variables sociodemográficas, socioeconómicas y de cambios de uso del suelo, para identificar en este contexto las estrategias de supervivencia desplegadas por los habitantes en el periodo 1990-2015. Para lograr el objetivo, se examinaron aspectos históricos, geográficos, así como la complejidad socioeconómica y sociodemográfica de la zona de estudio. Los resultados indican que Calpan ha sufrido transformaciones territoriales influenciadas por la crisis económica de las actividades primarias y el incremento poblacional. Las estrategias de supervivencia apoyadas en actividades primarias han disminuido y han aumentado las basadas en el sector terciario de la economía.

Palabras clave: Calpan, espacio, territorio, transformaciones socioeconómicas, población.

\section{Abstract}

In México, neoliberal policies encourage transformations in the territories and changes in survival strategies. Thus the aim of the study was carried out to explain the territorial transformations in the municipality of Calpan, from the analysis of variables; demographic, socioeconomic and land use changes, to identify in this context survival strategies deployed by the inhabitants in the period 1990-2015. To achieve the objective, historical, geographical aspects were examined, as well as socio-economic and socio-demographic complexity of the study area. The results indicate that territorial changes Calpan has been influenced by the economic crisis of the primary activities and population growth. Survival strategies supported by primary activities have decreased and have increased based on the tertiary sector of the economy.

Keywords: Calpan, space, territory, socio-economic, population. 


\section{INTRODUCCIÓN}

$\mathbf{E}$

1 objetivo del estudio fue identificar las transformaciones territoriales y las estrategias de supervivencia de las familias en el municipio de Calpan en el periodo 1990-2015, a partir del análisis de variables sociodemográficas, socioeconómicas y de cambios de uso del suelo. Para lograr el objetivo, se examinaron aspectos históricos, geográficos, así como la complejidad socioeconómica, política y cultural de la zona de estudio.

El documento se estructura en siete apartados, en el primero se presentan los antecedentes teóricos y empíricos del estudio, en el segundo se presentan los materiales y métodos empleados en la investigación, en el tercero se realiza un acercamiento a la configuración histórica del municipio. En el cuarto se describen las transformaciones sociodemográficas; en el quinto se analizan los aspectos socioeconómicos y en el sexto apartado se presentan las transformaciones del uso de suelo. Finalmente, en el séptimo apartado se presentan las conclusiones.

\section{GLOBALIZACIÓN, TERRITORIO Y NUEVA RURALIDAD}

Se abordan en este apartado, los elementos teóricos que guiaron el trabajo de investigación y su relación con la zona de estudio.

\section{Globalización económica}

La globalización ha trasformado profundamente la organización territorial y la producción de alimentos en la agricultura, con consecuencias en las dinámicas de reproducción socioeconómica de las familias. En México, López (2009), precisa que los principios de esta trasformación se fundamentaron en el objetivo de hacer compatible el modelo de desarrollo agrícola con la nueva política enfocada hacia la competitividad, las ventajas comparativas y la inserción de México en el proceso de internacionalización de la agricultura; bases de la globalización económica y cuya política se sustenta en el modelo neoliberal. Esta política neoliberal se establecía en la especialización productiva como principal factor de desarrollo y crecimiento económico, y donde los países más industrializados son los encargados de la producción de los bienes básicos de la alimentación, mientras que los países menos industrializados son los encargados de la producción 
de hortalizas, flores y frutas (Hausmann y Klinger, 2008). Al convertirse los granos básicos para la alimentación en un atributo de la producción de los países industrializados y al intensificarse la búsqueda de mercados por la colocación de los excedentes, la producción campesina minifundista de los territorios rurales resultó innecesaria, lo cual modificó las estrategias de supervivencia de las familias (Ramírez y Méndez, 2007). En México, la aplicación de políticas neoliberales ha incrementado los niveles de pobreza y marginación, debido a que la implementación de políticas y ajustes estructurales no han beneficiado a los campesinos o productores rurales familiares, sujetos a las reglas de un nuevo orden agrícola internacional que tiene como principales saldos la disminución de sus ingresos y empleos, así como la reestructuración de sus estrategias de supervivencia, y por ende, de sus territorios (Ramírez y Méndez, 2007; Rubio, 2006; Barkin, 1991; Calva, 1992; Villa, 2008). Ejemplo de lo anterior, es el municipio de estudio donde los actores involucrados y cuya principal actividad es la agricultura, han tenido que enfrentar en los últimos 30 años nuevas y diversas actividades para garantizar su supervivencia y permanencia territorial.

\section{Transformaciones territoriales}

En el estudio, el territorio es considerado como una construcción social a partir del espacio geográfico, y como lo menciona Llambi y Pérez (2007), el territorio (del latín terra) remite a cualquier extensión de la superficie terrestre habitada por grupos de humanos y delimitada (o delimitable); es la parte de la superficie terrestre delimitada en términos geográficos, administrativos o políticos. Por su parte Torres (2009), menciona que el territorio es un espacio socializado, apropiado y producido por sus habitantes, lo cual se integra al planteamiento de toda sociedad que ocupa un espacio y lo transforma en territorio. Para Rubio (2006), el territorio es hoy la unidad más visible del mundo rural, como una amalgama de procesos, conflictos, hallazgos: es, además, el núcleo central de la teoría conocida como nueva ruralidad.

Para Mançano (2009), es imposible comprender el concepto de territorio sin concebir sus relaciones de poder. Estas relaciones están determinadas por las políticas de desarrollo; por lo tanto, quien determina la política también define la forma de organización del territorio. Además, cada territorio es una totalidad, pero diferenciada por diversos factores, algunos de ellos son las relaciones sociales y las escalas geográficas. Esa totalidad se compone de fracciones que en lo individual son totalidades compuestas por su multidimensionalidad: social, cultural, económica y espacial. Asi- 
mismo, Velásquez (2012), considera al territorio como una construcción social e histórica de un espacio geográfico, producto de la especialización del poder y de las relaciones de conflicto que de ella se derivan. Constituyéndose a partir de la apropiación económica, ideológica y política (social) del espacio por los grupos sociales que dan una representación específica de sus intereses y su historia para garantizar su reproducción y permanencia en un espacio geográfico determinado.

En las definiciones anteriores, es posible rescatar tres aspectos a considerar en el análisis y explicación de las transformaciones de un territorio: el aspecto socio-histórico, económico y el uso de suelo o geográfico. Al respecto Gorenstein (2015), añade que el término territorio involucra nuevas nociones y categorías analíticas elaboradas en el amplio campo de las ciencias sociales, además de la economía y la geografía, en el marco de una perspectiva multidimensional que indaga, analiza y explica las transformaciones en el territorio.

Estas propuestas vinculan el análisis del territorio a partir de tres aspectos que guían al presente trabajo: el ámbito social que involucra aspectos históricos y demográficos; el económico que analiza aspectos relacionados con las prácticas de actividades económicas, como la evolución de la población económicamente activa y productividad, y desde la geografía, los cambios de uso de suelo en el municipio de estudio.

Para fines de esta investigación, y en función de la literatura consultada, se define al territorio como un espacio geográficamente localizado, con una historia particular, delimitado y apropiado por diversos actores que interactúan en él, y que establecen relaciones sociales de convivencia, de poder y de conflicto; se le concibe así, como un espacio dinámico y en constante mutación, derivado de la persistencia en las transformaciones de su totalidad — económica, política, social, cultural o ambiental—, que se va adecuando a las diversas situaciones que presenta, lo cual confecciona al territorio, y modifica y es modificado necesariamente por las estrategias de supervivencia ${ }^{1}$ de sus habitantes.

\section{Nueva ruralidad}

Resultado de la aplicación de las políticas neoliberales, la mayoría de los gobiernos abandonó las políticas sectoriales, las estrategias de desarrollo rural y se concentraron en las políticas macroeconómicas (Plaza, 2002).

\footnotetext{
${ }^{1}$ En este trabajo las estrategias de supervivencia son consideradas como las actividades económicas efectuadas para garantizar un ingreso que les permita la reproducción de la formación material, social y biológica de los habitantes (Duque y Pastrana, 1973; Lomnitz,1975; Hintze, 1989; Bourdieu, 2011).
} 
Sin embargo, los mecanismos de dominación y poder ejercidos por los mercados agroalimentarios internacionales sobre la producción y comercialización; así como las limitantes condiciones económicas de vida de los pequeños productores agrícolas, terminaron marchitando estas propuestas. El fracaso de la modernización agrícola impulsada en México por el modelo económico neoliberal, y la internacionalización de la agricultura en un contexto de globalización, generaron una diversidad de cambios en las funciones atribuidas tradicionalmente a los espacios rurales en México. Estos fueron analizados por diversas investigaciones generando debates y propuestas teóricas como la "Nueva Ruralidad". Este enfoque surge a partir de los cambios estructurales que sufren las sociedades rurales, originados y obligados por el modelo de desarrollo económico global (Pérez, 2001).

El enfoque de Nueva Ruralidad emerge de las transformaciones del campo latinoamericano donde la relación campo-ciudad es ahora mucho más compleja, por el intercambio desigual y la migración de los pobres del campo a las ciudades para conformar el ejército industrial de reserva, así lo indica Grammont de (2016), y añade que la vida rural, tradicionalmente asociada con la actividad agropecuaria, abriga ahora una diversidad de actividades y relaciones sociales que vinculan a las familias rurales con la actividad industrial y de servicios, haciendo una sociedad rural más diversificada.

\section{Materiales y métodos de la investigación}

Se realizó una combinación de investigación histórica y descriptiva, en la cual se sustentaron los acontecimientos del pasado que permitieron el análisis de las transformaciones económicas y territoriales en el municipio de Calpan. Se emplearon diversas técnicas cualitativas como son, la observación in situ de la realidad, entrevista semi-estructurada a informantes clave, además de la revisión de fuentes secundarias, entre ellas, la revisión del archivo parroquial, archivo civil municipal, archivo histórico e información bibliográfica. Posteriormente la delimitación, fundamentación, análisis e interpretación de la investigación se efectuó bajo la mirada de las unidades analíticas de territorio y nueva ruralidad.

\section{Configuración histórica territorial del municipio de Calpan}

La configuración del territorio también es resultado de la representación, construcción y apropiación que realizan diversos actores involucrados, así como las relaciones que lo impactan en una simbiosis dialéctica en la cual tanto el territorio como el grupo humano se transforman en el recorrido 
histórico, por ello la importancia de revisar la trayectoria histórica del espacio (Velásquez, 2012).

Calpan (del náhuatl sobre el caserio o donde hay muchas casas) población importante en la región del valle de Puebla (Granados, 1935). Representando un municipio histórico, con un pasado religioso, lleno de vida y engalanado por los volcanes; en palabras de Meraz Quintana:

El pequeño pueblo mexicano de Calpan, en el estado de Puebla, se encuentra situado en las faldas de los míticos volcanes Popocatépetl e Iztaccíhuatl, en su vertiente hacia la gran ciudad de Puebla. Su historia, tan extensa y rica como su ubicación, se remonta muchos siglos atrás; se ha visto influida por las erupciones de dichos volcanes por lo que la fundación destrucción y refundación de asentamientos humanos se ha llevado a cabo en varias ocasiones desde el periodo denominado pre-clásico, hacia aproximadamente 1500 a.C. (Meraz y Guerrero, 2011: 1).

Actualmente el municipio de Calpan se localiza entre los paralelos $19^{\circ}$ $03^{\prime}$ y $19^{\circ} 09^{\prime}$ de latitud norte; los meridianos $98^{\circ} 23^{\prime}$ y $98^{\circ} 35^{\prime}$ de longitud oeste; altitud entre 2,200 y 3,200 metros (INEGI, 2015b). Calpan es uno de los 217 municipios que conforman el estado de Puebla, con una superficie de $67 \mathrm{~km}^{2}$; en este municipio se encuentran, además del pueblo cabecera, dos pueblos más (San Mateo Ozolco y San Lucas Atzala) y rancherías esparcidas en su territorio (Figura 1).

La Orografía del municipio está determinada por su ubicación con respecto a la Sierra Nevada y el eje neo-volcánico. Meraz y Guerrero (2011), indican que la relación entre la ubicación del municipio y la Sierra Nevada son muy importantes ya que justamente esta Sierra, que delimita la cuenca de Puebla al occidente, en épocas antes de la conquista de los Españoles, fue la que sirvió como frontera entre los señoríos independientes de esta región: Tlaxcallan, Huexotzinco junto con Calpan y Cholollan, y que además esta Sierra Nevada brindaba protección y sustento muy directamente tanto a Huexotzinco como a Calpan, y en gran medida a Tlaxcallan.

Debido a la cercanía con la Sierra Nevada que divide al municipio y la ubicación de los volcanes, en Calpan, a pesar de que predominan suelos de barro, esta característica no afecta a la agricultura (principal actividad económica en el municipio), pues los barros están cubiertos por una capa coluvial, es decir, han recibido capas de tierra más fértil debido a los desplazamientos provenientes de las montañas más arriba y las cenizas de los Volcanes (Meraz, 2006). 
Figura 1: Ubicación Geografica de Calpan, Puebla-Mexico

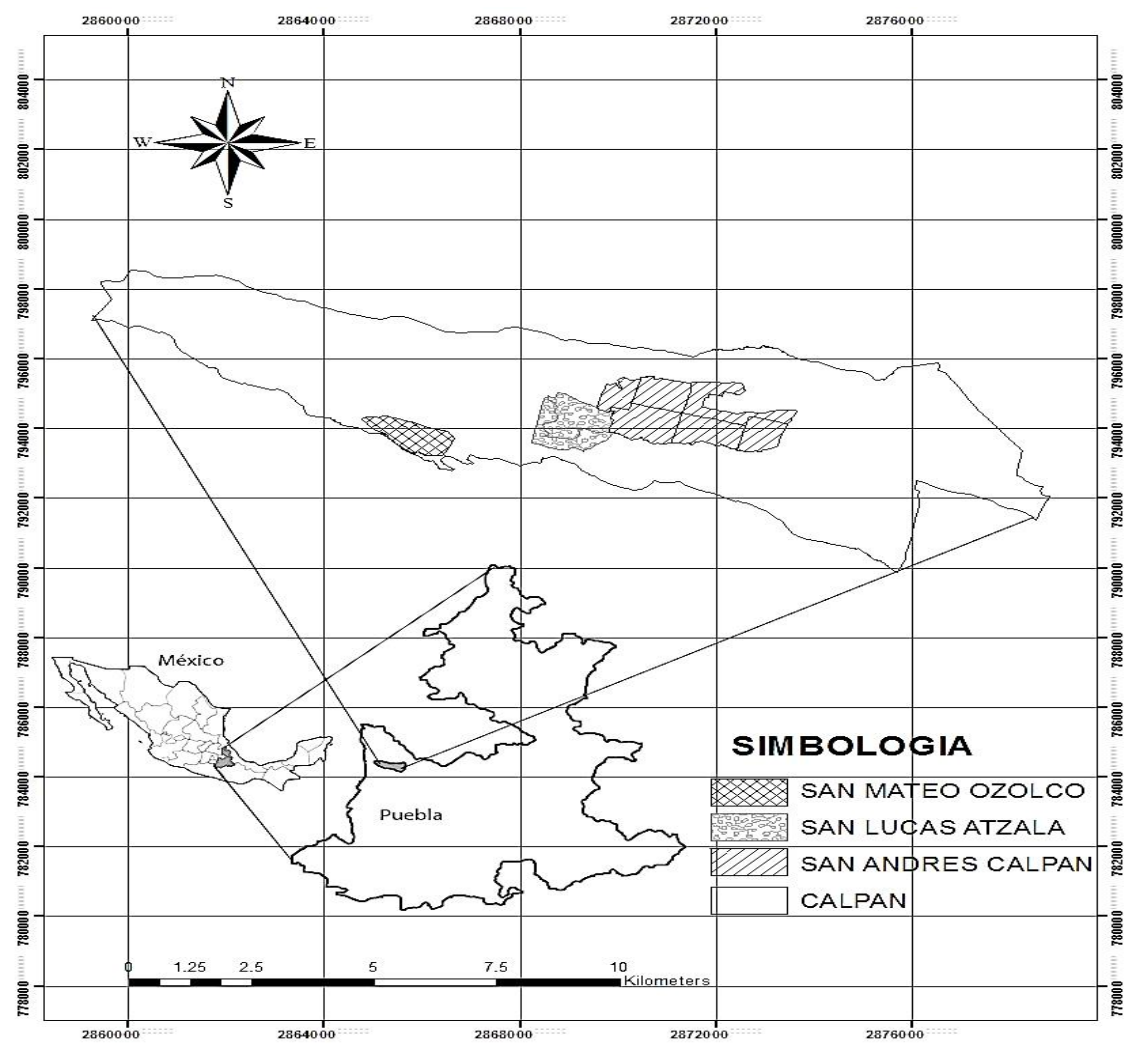

Fuente: elaboración propia con datos del INEGI 2015c. Las cotas y la escala hacen referencia únicamente al espacio geográfico que ocupa el municipio de Calpan.

En las capas más antiguas de estos suelos se encuentra el tepetate, barro muy duro, accesible a lo largo de las barrancas formadas por los ríos donde han quedado al descubierto las capas propensas al endurecimiento. Este material fue ampliamente utilizado en la vivienda tradicional calpaneca desde tiempos ancestrales (Meraz y Guerrero 2011). Y es que hasta hace unos años en Calpan se contaba con una vasta arquitectura basada en el tapial$^{2}$; en 1995 el Instituto Nacional de Estadística y Geografía (INEGI), contabilizó 2,493 viviendas, de las cuales 52 por ciento eran de tapial y adobe. La técnica de tapial que bien aunque modesta, hermosa e intere-

${ }^{2}$ El tapial es un sistema de construcción con base en tierra húmeda compactada in-situ, consiste básicamente en rellenar un encofrado con capas de tierra de $30 \mathrm{~cm}$ compactando cada una de ellas con un pisón. Generalmente la cimentación y el sobrecimiento son de Pirca: piedras grandes adheridas con barro (Castellanos, 2014). 
sante a la vez, que por sus características y su uso en variadas estructuras (casas, graneros, bardas, etc.) ha sido objeto de múltiples estudios (Meraz y Guerrero, 2011: 34).

La ubicación de los asentamientos humanos en el municipio se basaba en la disponibilidad y acceso del agua para realizar sus actividades cotidianas (Meraz, 2006). En el municipio la hidrología se localiza en la cuenca alta del Río Atoyac, una de las más importantes en el estado de Puebla. Arroyos intermitentes y permanentes provenientes de las estribaciones del Iztaccíhuatl, recorren el municipio de Noroeste a Sureste; destacan el Alseseca, Acteopan, Actipitzi y Atlanepantla, todos ellos tributarios del Río Atoyac. Los ventisqueros del Iztaccíhuatl pueden almacenar aguas y alimentar los poblados y terrenos de sus faldas en la época de sequía. Las rocas y los suelos dejan infiltrar el agua hasta grandes profundidades, por lo que al pie de los volcanes puede obtenerse agua de pozos durante todo el año (INAFED, 2010).

En cuanto al clima, el municipio de estudio presenta un clima templado sub-húmedo con lluvias en verano (85.11 por ciento) y semifrío sub-húmedo con lluvias en verano (14.89 por ciento) y una temperatura media anual que va de los 12 a $\operatorname{los} 18^{\circ} \mathrm{C}$, aunque en invierno la temperatura puede bajar a los $-3^{\circ} \mathrm{C}$. Por otro lado el rango de precipitación se encuentra entre $900 \mathrm{y}$ 1, $100 \mathrm{~mm}$ anuales (INEGI, 2015b).

Debido al clima, el agua y su ubicación estratégica cercana a la sierra Nevada y los volcanes que benefician el tipo de suelo, en el municipio de Calpan, se permitió la prosperidad en la agricultura, principal actividad, tanto en épocas precolombinas como actuales; sin embargo, dicha bonanza agrícola no estuvo exenta de conflictos y transformaciones culturales y geográficas que sufrió Calpan a lo largo de su historia, para llegar a ser el territorio que representa en la actualidad. Pueblo, de orígenes Olmecas Xicalancas, fue antes de la Conquista una pequeña entidad independiente, muy ligada al reino de Huejotzingo (Virve, 1981). Durante la conquista, los calpeños pertenecieron a la alianza encabezada por los tlaxcaltecas quienes se sometieron a la dominación española. El interés del conquistador Hernán Cortés en dicho espacio, era por que representaba una vía de comunicación entre el puerto de Veracruz y la capital azteca (Tenochtitlàn) (Meraz, 2006). Virve menciona que:

A la llegada de los españoles existían aproximadamente cuarenta mil personas, cuyo número disminuyó a causa del alto porcentaje de mortandad causado por las epidemias y explotación de la mano de obra para la construcción de la ciudad de Puebla (Virve, 1981: 2). 
Precisamente en el año de 1530 es cuando el territorio pasa a manos del conquistador Diego de Ordaz, fundándose el poblado de San Andrés Calpan con un total de cinco mil indios (Meraz, 2006). Enseguida es cuando la labor religiosa culmina la conquista iniciando con la fundación de una casa franciscana. Acosta y Pérez (2004), indican que la evangelización del municipio de Calpan fue considerada como una de las doctrinas franciscanas más importantes de la Nueva España, prueba de ello es el convento franciscano y sus capillas posas que fueron fundadas en 1548 por fray Juan de Alameda.

La evangelización no alteró en cierto modo la tradición agrícola existente en el municipio, ya que al parecer Calpan como población mestiza siempre fue un núcleo agrícola cuya principal actividad económica fue la siembra de la milpa, ${ }^{3}$ que se mantiene como tal y que hasta este siglo estuvo muy ligado a la Hacienda de Chahuac, de la cual aún existen vestigios en las cercanías del pueblo. Sin embargo, si agregó nuevas costumbres en el manejo de los cultivos, prácticas basadas en la religión como la bendición de la semilla el 2 de febrero. Además la presencia europea modificó la siembra de la milpa (maíz-frijol-calabaza) en el territorio combinando ésta con hileras de árboles frutales de granada, higo, limón, manzana, pera y durazno (Meraz y Guerrero, 2011).

Por lo antes dicho, el paisaje agrícola como elemento del espacio geográfico, sufre transformaciones importantes en el municipio, ya que previo a la conquista y a la Colonia, era agrícola con cierta homogeneidad a partir del cultivo de la milpa (maíz-frijol-calabaza). De esta forma no solo se produjo un mestizaje en la población, sino también en el paisaje agrícola, ya que se podía observar en él una combinación de cultivos de milpa intercalada con árboles frutales (Méndez et al. 2017).

La presencia española en el territorio no solo modificó las prácticas en el manejo del cultivo con la incorporación de nuevos productos (trigo, pepino, garbanzo, etc.) y nuevas herramientas (arado, yunta, etc.), sino que modificaron el espacio ocupado por el municipio debido a la incorporación de animales de pastoreo (borregos, chivos, etc.), así como animales de tiro (caballos, bueyes, mulas etc.) utilizados en actividades agrícolas. Meraz y Guerrero (2011), añaden que la introducción de nuevos animales en el municipio de Calpan provocó cambios notables tanto en la agricultura como en el transporte y la alimentación.

${ }^{3}$ La milpa es un término que deriva del náhuatl, mil-pa. La milpa produce de forma conjunta maíz (Zea mays), frijol (Phaseolus vulgaris $L$ ), calabaza (Cucurbita pepo L) y otros cultivos que son complementarios tanto nutricional como ecológicamente. 
Dichos cambios y transformaciones, se acentúan en la actualidad; Meraz, añade al respecto:

En el municipio de Calpan la superficie del territorio cultivado puede presentar cambios promovidos por la aparición del arado y la yunta introducidos por los españoles, pero el carácter comercial de la agricultura en la actualidad los ha acentuado, a través de una lenta mecanización. De ahí que la superficie de cultivos fuera probablemente menor antaño, a pesar de que existían tierras trabajadas por macehuales (que poseían tierra propia) y terrazgueros (que trabajaban la tierra de otros), que debían rendir un tributo para sostener a las instituciones y sus representantes (Meraz, 2006: 39).

De manera general se considera que Calpan no cambió su estructura urbana y social durante el periodo de la Independencia de México, ya que tanto la arquitectura como la traza y sus cambios denotan una economía basada en pequeños agricultores. Meraz y Guerrero (2011), agregan que por la estructura urbana se infiere que hacia el Porfiriato el poblado gozaba de cierta bonanza, factiblemente un hecho que modificó esta situación fue la repartición de tierras hecha en el siglo XX con la reforma agraria, cuando desapareció la Hacienda de Chahuac y se creó el Ejido de Calpan.

Calpan fue constituido como municipio en 1835, y su historia enmarca transformaciones en las actividades y la construcción de su territorio; sin embargo, el siglo XXI experimenta en el territorio, transformaciones territoriales que se reflejan en la estructura de su población, su economía, el espacio y en las estrategias de supervivencia desplegadas por los habitantes.

\section{Transformaciones sociodemográficas}

El análisis de las características sociodemográficas de un territorio, resume el proceso histórico del comportamiento socioeconómico, político y cultural de una sociedad y, a su vez, configura la estructura y dinámica demográfica que observará dicha población en su futuro tanto a mediano como a largo plazo (López, 2009). Para Calpan, la Tabla 1 muestra como su población se incrementó en 19 por ciento en un periodo de 25 años, al pasar en 1990 de 11,967 habitantes a 14,280 en 2015. Asimismo, se observa un crecimiento de la población rural ${ }^{4}$ en el mismo periodo de análisis, al registrar cuatro por ciento del total de la población en 1990 y 28 por ciento para 2015. Los datos indican también, que la población que habla una lengua indígena se incrementó en tres por ciento.

\footnotetext{
${ }^{4}$ Poblaciones con menos de 2500 habitantes.
} 
Transformaciones territoriales y estrategias de superviviencia: el caso del municipio .../J.L. LÓPEZ GONZÁLEZ et al.

Tabla 1: Información general de la población en el municipio de Calpan

\begin{tabular}{lrr}
\hline Indicadores & 1990 & 2015 \\
\hline Población total & 11,967 & 14,280 \\
Hombres & 5,915 & 6,706 \\
Mujeres & 6,052 & 7,574 \\
Población urbana & 11,455 & 9,874 \\
Población rural & 512 & 3,856 \\
Población según condición de habla indígena & & \\
5 años o más & 2,193 & 2,260 \\
Densidad de Población $\left(\mathrm{hab} / \mathrm{km}^{2}\right)$ & 179 & 205 \\
\hline
\end{tabular}

Fuente: elaboración propia a partir de datos obtenidos de los anuarios estadísticos elaborados por el INEGI de 1990 y 2015 a.

Los incrementos poblacionales citados, responden básicamente a su dispersión geográfica por todo el municipio, dicho fenómeno es consecuencia de intereses recientes de los habitantes por acercase a vías de comunicación que les faciliten el acceso a municipios donde puedan ofertar su mano de obra, dando lugar a rancherías de reciente creación como lo son: San Bartolo (49 habitantes), El palmar (266 habitantes), San Lorenzo (19 habitantes), Tlapacoya (19 habitantes), San Lucas Atzala (2,483 habitantes), Pueblo Nuevo (558 habitantes), Chahuac (52 habitantes), Dolores (77 habitantes), Tepectipa (322 habitantes) y Las Animas (11 habitantes) (INEGI, 2015b).

El crecimiento de la población se ha reflejado en el incremento del número de localidades en el municipio. En 1990, el INEGI, reportó la existencia de cuatro localidades, veinticinco años después se incrementó a 13 localidades. Sin embargo, para 2015 solo tres localidades son consideradas las más importantes por su densidad de población, San Andrés Calpan, San Mateo Ozolco y San Lucas Atzala. Mientras para 1990 la mayor población se distribuía entre las localidades de San Andrés Calpan con 8,828 habitantes, San Mateo Ozolco 2,627 habitantes y Pueblo Nuevo 409 habitantes; en 2015 cambia la distribución y ahora San Andrés Calpan concentra 7,161 habitantes, San Lucas Atzala 2,483 habitantes, San Mateo Ozolco 2,713 y Pueblo Nuevo 558.

Por su parte las pirámides poblacionales del municipio (Figura 2), muestran que la parte más ancha en ambos años (1990-2015) se ubica en la población que tiene entre 0 y 14 años de edad, una estructura de población joven; en 1990 se concentra 42 por ciento en edades de 0 a 14 años, mientras que para el año 2015 es de 32 por ciento. 
Figura 2: Pirámides poblacionales del Municipio de Calpan 1990-2015

Piramide poblacional de 1990

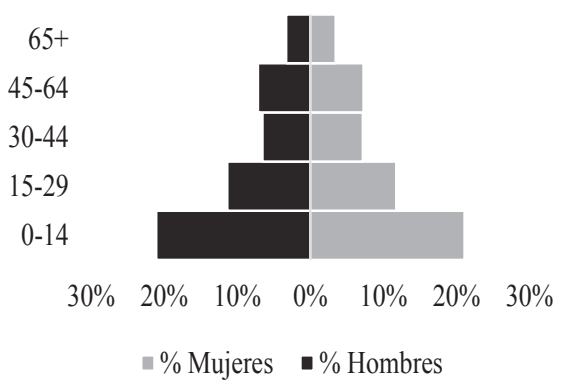

Piramide poblacional 2015

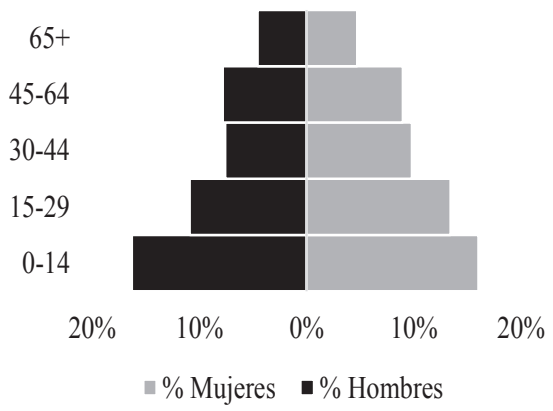

Fuente: elaboración propia con datos del censo de población y vivienda 1990-2015, INEGI 2015a.

Es decir, disminuyó diez por ciento en 20 años, sin embargo predomina en el periodo. La población adulta está ubicada en el rango de edad de 15 a 64 años y está representada por 53 por ciento para el año de 1990, y por 63 por ciento para 2015.

La población femenina prevalece sobre la masculina, entre el rango de edad de 15 a 64 años, mientras que el rango de edad de 0 a 14 no existen diferencias entre hombres y mujeres ya que representan el mismo porcentaje, 21 por ciento para 1990 y 16 por ciento para 2015. Este dato podría explicarse por el hecho de que existe mucha migración en el municipio, tan solo en San Mateo Ozolco en el 2015 se registró que 37 por ciento de su población habría migrado a Estados Unidos (INEGI, 2015b), y es que los hombres entre 15 a 29 años salen de su localidad de origen para buscar otras formas de empleo, mientras que las mujeres se quedan en la localidad (Bustamante et al., 1998; CONAPO, 2011).

Las condiciones de pobreza y marginación, son factores que potencian la expulsión de los habitantes (Jiménez, 2008). Para Calpan, la migración registrada entre 1990 y 2015 se duplicó, pasando de tres por ciento del total de la población a seis por ciento (INEGI 1990 y 2015b).

El Consejo Nacional de la Población (CONAPO, 2010), relaciona la marginación media y la pobreza con la migración internacional. En la Tabla 2 se observa que el municipio de estudio se encuentra en un grado medio de marginación para 2015, después de haber registrado un grado alto en 1990. 
Tabla 2: Índice de marginación e indicadores para el municipio de Calpan, Puebla, 1990-2015

\begin{tabular}{lcr}
\hline Indicador & 1990 & 2015 \\
\hline Índice de marginación $^{(*)}$ & 0.1528 & 0.2074 \\
Grado de marginación $^{(*}$ & Alto & Medio \\
\hline Fuente: elaboración propia con base en datos de CONAPO con base en el INEGI. INEGI, \\
2015a.
\end{tabular}

Por su parte al examinar el Índice de Desarrollo Humano (IDH), el cual se describe en la Tabla 3, se observa que para el caso de Calpan es Medio; la tasa de mortalidad ha disminuido, el alfabetismo ha aumentado, el índice de ingreso aumentó, así como la educación y salud.

Tabla 3: Índice de desarrollo Humano para el Municipio de Calpan 19902015

\begin{tabular}{lrr}
\hline Indicador & 1990 & 2015 \\
\hline Índice de Desarrollo Humano $^{*}$ & 0.69 & 0.74 \\
Grado de Desarrollo Humano $^{(*)}$ & Medio & Medio \\
Tasa de mortalidad infantil & 30.68 & 28.95 \\
Tasa de alfabetismo & 75.27 & 79.81 \\
Índice de salud & 0.762 & 0.792 \\
Índice de educación & 0.717 & 0.767 \\
Índice de ingreso & 0.588 & 0.638 \\
\hline
\end{tabular}

Fuente: elaboración propia a partir de datos obtenidos de los anuarios estadísticos elaborados por el INEGI de 1990 y 2015a. Los datos mostrados corresponden a la información más reciente publicada por el PNUD-México.

Para Peláez (2012), la reducción de la fecundidad y el aumento de la esperanza de vida que tiene lugar durante el proceso de cambio demográfico alteran de manera irreversible la composición por edades de la población, lo que da lugar a una estructura etaria más favorable al crecimiento económico y a la adopción de ciertas prácticas que refuerzan el desarrollo. Sin embargo resultaría poco provechoso dejarnos guiar por el IDH ya que como bien lo indica Tapia: "Ni está muy claro que cosa mide ese índice, ni, menos aún, que la cosa medida sea desarrollo humano" (Tapia, 1995: 74).

Al analizar el IDH estimado por el Programa de las Naciones Unidas para el Desarrollo (PNUD), el grado de marginación estimado por el Consejo Nacional de Población (CONAPO), así como los indicadores sociales estimados por el Consejo Nacional de Evaluación (CONEVAL), se observan datos contrastantes, por un lado el IDH muestra un grado medio de desarrollo, mientras que la marginación también es media, sin embargo los 
indicadores sociales expuestos en la Tabla 4, muestran que 80 por ciento de la población del municipio vive en situación de pobreza y 20 por ciento de la población tiene pobreza extrema.

Mientras los indicadores de desarrollo y marginación muestran que se ha mejorado la condición de vida y que aparentemente la población no está expuesta a vulnerabilidades sociales, por otra parte los indicadores sociales señalan que Calpan se encuentra herido por una profunda desigualdad de oportunidades de participación en el proceso de desarrollo y de disfrute de sus beneficios, dado que 82 por ciento de la población percibe un ingreso inferior a la línea de bienestar mínimo (Tabla 4).

Tabla 4: Indicadores sociales del municipio de Calpan, Puebla para el año 2015

\begin{tabular}{lrr}
\hline Indicadores & Porcentaje & Número de personas \\
\hline Población en situación de pobreza & 80 & 8,239 \\
Población en situación de pobreza moderada & 60 & 6,157 \\
Población en situación de pobreza extrema & 20 & 2,030 \\
Población con ingreso inferior a la línea de bienestar & 82 & 8,308 \\
\hline
\end{tabular}

Fuente: Estimaciones del CONEVAL 2015 con base en INEGI, 2015a.

Ratificando la situación de pobreza en la que se encuentra el municipio de Calpan, en la Tabla 5 se puede observar la evolución de la pobreza Alimentaria $^{5}$, de Capacidades ${ }^{6}$ y de Patrimonio ${ }^{7}$ en el periodo de 1990-2015, así como el grado de cohesión social ${ }^{8}$ medido a través del coeficiente de Gini, que indica que, para el municipio la cohesión social es baja, también con base en estos datos el CONEVAL (2015), indica que Calpan se encuentra en un polo de alta marginación. ${ }^{9}$ De 1990 a 2015, la pobreza alimentaria disminuyó en tres por ciento, la de Capacidades solo uno por ciento, sin embargo la pobreza de patrimonio aumentó cuatro por ciento.

\footnotetext{
${ }^{5}$ Incapacidad para obtener una canasta básica alimentaria, aun si se hiciera uso de todo el ingreso disponible en el hogar para comprar sólo los bienes de dicha canasta (CONEVAL, 2014).

${ }^{6}$ Insuficiencia del ingreso para adquirir el valor de la canasta alimentaria y efectuar los gastos necesarios en salud y educación, aun dedicando el ingreso total de los hogares nada más que para estos fines (CONEVAL, 2014).

${ }^{7}$ Insuficiencia del ingreso disponible para adquirir la canasta alimentaria, así como realizar los gastos necesarios en salud, vestido, vivienda, transporte y educación, aunque la totalidad del ingreso del hogar fuera utilizado exclusivamente para la adquisición de estos bienes y servicios (CONEVAL, 2014).

${ }^{8}$ La medición de la cohesión social adoptada por el CONEVAL incorpora indicadores que ayudan a conocer el nivel de desigualdad económica y social de la población a nivel nacional, estatal y municipal, así como indicadores de redes de apoyo e intercambio social a nivel estatal. Lo anterior permite aproximarse al nivel de equidad y solidaridad que existe en una sociedad (CONEVAL, 2014).

${ }^{9}$ Polo izquierdo (de alta marginación): la mayoría de su población presenta condiciones precarias en sus viviendas, bajos ingresos y con bajos niveles de educación (CONEVAL, 2014).
} 
Transformaciones territoriales y estrategias de superviviencia: el caso del municipio ... /J.L. LÓPEZ GONZÁLEZ et al.

Tabla 5: Evolución de la pobreza por ingresos en el municipio de Calpan 1990,2000 y 2015

\begin{tabular}{lrrr}
\hline & 1990 & 2000 & 2015 \\
\hline Pobreza Alimentaria & 38.3 & 57.5 & 35.3 \\
Pobreza de Capacidades & 48.2 & 67.4 & 46.7 \\
Pobreza de Patrimonio & 71.5 & 85.4 & 74.7 \\
Grado de Cohesión Social (coeficiente de Gini) & 0.377 & 0.376 & 0.330 \\
\hline Fuente: estimaciones del CONEVAL, 2014; 2015; los Censos de Población y Vivienda 1990 y \\
2000, y la Encuesta Intercensal 2015.
\end{tabular}

El aumento de la pobreza en todos sus indicadores en el año 2000 en el municipio, tiene su explicación en la crisis financiera de 1994 y 1997 que habría contraído la economía del país en seis por ciento y el Producto Interno Bruto (PIB) per cápita más de siete por ciento, este cambio junto con una elevada inflación, ocasionó una reducción de los salarios en más de diez por ciento.

\section{Transformaciones socioeconómicas}

La persistencia de los altos niveles de pobreza en México y en el municipio de Calpan, está altamente relacionada con el comportamiento de distintas variables macroeconómicas, por lo cual es necesario hacer hincapié en el contexto en el que se ha desarrollado nuestro país en los últimos 20 años. Pensar en el entorno nacional permitirá comprender, de manera más adecuada, las transformaciones socioeconómicas, que se han presentado en el municipio estudiado a partir de 1990 y hasta el 2010, y cómo estas transformaciones han modificado las estrategias de supervivencia desplegadas por los habitantes del municipio.

Se destacan tres eventos que han tenido un efecto significativo en la evolución de la pobreza: la crisis económica de 1994 a 1996; el crecimiento acelerado que siguió a dicha crisis y que se extendió hasta el año 2000; y la actual crisis económica, iniciada en 2007 y en la cual se han presentado un aumento acelerado del precio de los alimentos, una disminución de la actividad económica y crecientes niveles de desempleo (CONEVAL, 2014). Las consecuencias de dichas crisis se hicieron muy notables en la agricultura y es que durante los años noventa en adelante el sector primario sufrió transformaciones definitivas, ya que se eliminaron en buena medida los sistemas de protección y fueron sustituidos por mecanismos de libre mercado que permitirían a México insertarse en el proceso de globalización (Villa, 2008). Lo anterior sin duda afectó a las familias en Calpan, ya que la mayoría de su población se encuentra ocupada en el sector primario de la economía. 


\section{Estrategias de supervivencia}

En México tras la aplicación de políticas neoliberales, las familias modifican sus estrategias de supervivencia, por medio de la diversificación de actividades o pluriactividad. Para Sacco y Velleda (2007), la pluriactividad es un fenómeno asociado fundamentalmente a la agricultura familiar y forma parte de las estrategias de supervivencia adoptadas por los pequeños agricultores. Tales estrategias se podrían definir como el desarrollo o la combinación de diversas actividades (agrícolas y no agrícolas) que pueden ser realizadas dentro o fuera de las unidades de producción (o dentro o fuera de la comunidad donde radica el productor). Para el caso del municipio de Calpan, datos de la Tabla 6 muestran que la población ocupada en el sector primario disminuye para el año 2015 , mientras la población ocupada en el sector secundario y terciario aumenta cuatro y 11 por ciento respectivamente. El crecimiento del sector terciario y secundario, ha ocasionado que las personas dedicadas al sector primario participen en dichos sectores para complementar sus ingresos (Grammont de, 2006; Galindo, 1994).

La información obtenida en campo, permitió conocer que la agricultura de tiempo parcial es una constante actual en el municipio, ya que se complementa esta actividad con trabajos de albañilería, plomería, panadería, choferes de taxi. Es cierto que la pluriactividad puede resultar una eficaz estrategia de supervivencia para mejorar el ingreso de los hogares rurales; así lo han demostrado diversos autores que han estudiado este fenómeno (Grammont de, 2006; Janvry de y Sadoulet, 2004). Sin embargo, otros estudios (Anseeuw y Laurent, 2007; Damián et al., 2004), han señalado que los hogares que han diversificado sus ingresos, han reducido la renta agrícola, disminuido su especialización en cuanto al manejo de los cultivos y su dependencia de la agricultura es más baja que la de los hogares subordinados a las actividades agrícolas.

En la Tabla 6 se muestra que para 1990 la población ocupada fue de 2,353 personas, de las cuales el INEGI indica que 73 por ciento se ocupa en el sector primario, ocho por ciento en el secundario y 19 por ciento en el terciario de la economía. Para 2015, 57 por ciento se ocupa en el sector primario, 13 por ciento en el sector secundario y 30 por ciento en el sector terciario (INEGI, 1990 y 2015c).

Es trascendental que del periodo de 1990 a 2015 la población dedicada al campo ha disminuido 16 por ciento, y es que el nuevo orden internacional lo único que ocasiona es marginar al pequeño productor minifundista al no poderse insertar en la estructura exportadora (Rubio, 2006). El trasfondo de esta situación es que se han polarizado las posibilidades de desarrollo en el campo. 
Tabla 6: Porcentaje de la población ocupada por tipo y rama de la actividad económica realizada en Calpan para 1990-2015

\begin{tabular}{|c|c|c|}
\hline & $\begin{array}{r}\text { Población } \\
\text { ocupada } 1990 \\
\end{array}$ & $\begin{array}{r}\text { Población } \\
\text { ocupada } 2015 \\
\end{array}$ \\
\hline $\begin{array}{l}\text { Población total que realiza actividades del } \\
\text { sector primario }\end{array}$ & 1720 & 2520 \\
\hline $\begin{array}{l}\text { Agricultura, ganadería, aprovechamiento } \\
\text { forestal, pesca y caza }(\%)\end{array}$ & 73 & 57 \\
\hline $\begin{array}{l}\text { Población total que realiza actividades del } \\
\text { sector secundario (\#) }\end{array}$ & 195 & 595 \\
\hline Minería (\%) & 0 & 0 \\
\hline $\begin{array}{l}\text { Electricidad, agua y suministro de gas por } \\
\text { ductos al consumidor }(\%)\end{array}$ & 0 & 3 \\
\hline Construcción & 6 & 7 \\
\hline Industrias manufactureras & 2 & 3 \\
\hline $\begin{array}{l}\text { Población total que realiza actividades del } \\
\text { sector terciario (\#) }\end{array}$ & 438 & 1600 \\
\hline Comercio $(\%)$ & 8 & 10 \\
\hline Transportes, correos y almacenamiento (\%) & 0 & 0 \\
\hline Información en medios masivos (\%) & 0 & 0 \\
\hline Servicios financieros y de seguros $(\%)$ & 0 & 0 \\
\hline $\begin{array}{l}\text { Servicios inmobiliarios y de alquiler de } \\
\text { bienes muebles }(\%)\end{array}$ & 0 & 0 \\
\hline $\begin{array}{l}\text { Servicios profesionales, científicos y } \\
\text { técnicos }(\%)\end{array}$ & 0 & 0 \\
\hline Dirección de corporativos y empresas (\%) & 0 & 0 \\
\hline $\begin{array}{l}\text { Servicios de apoyo a los negocios y manejo } \\
\text { de desechos }(\%)\end{array}$ & 0 & 0 \\
\hline Servicios educativos $(\%)$ & 3 & 4 \\
\hline Servicios de salud y de asistencia social (\%) & 3 & 4 \\
\hline $\begin{array}{l}\text { Servicios de esparcimiento cultural y } \\
\text { deportivo, y otros servicios recreativos (\%) }\end{array}$ & 1 & 5 \\
\hline $\begin{array}{l}\text { Servicios de alojamiento temporal y de } \\
\text { preparación de alimentos y bebidas }(\%)\end{array}$ & 3 & 5 \\
\hline $\begin{array}{l}\text { Otros servicios excepto actividades del } \\
\text { Gobierno }(\%)\end{array}$ & 0 & 0 \\
\hline Actividades del Gobierno (\%) & 1 & 2 \\
\hline $\begin{array}{l}\text { Servicios de Intermediación Financiera } \\
\text { Medidos Indirectamente }(\%)\end{array}$ & 0 & 0 \\
\hline Población Ocupada Total & 2,353 & 4,715 \\
\hline
\end{tabular}


Por una parte, la crisis de las actividades productivas tradicionales y, por otra, la modernización de las explotaciones agropecuarias orientada a la exportación, que ha dado lugar al surgimiento de nuevos actores rurales que realizan la agricultura como actividad secundaria y priorizan las actividades del sector servicios (Echanove y Steffen, 2005).

El nuevo orden agrícola internacional no solo influye en la diversificación de actividades, sino también en las tendencias de cambio y recomposición de la producción agrícola en el municipio de Calpan. En el periodo de 1990-2015, en el caso del maíz la superficie sembrada disminuyó diez por ciento, al pasar de un registró de 83 por ciento de la superficie total sembrada en 1990 y 73 por ciento para 2015 (Tabla 7).

Tabla 7: Superficie sembrada (miles de hectáreas) en el municipio de Calpan 1990-2015

\begin{tabular}{lrrrr}
\hline Cultivo & 1990 & 2000 & 2010 & 2015 \\
\hline Maíz grano & 3,080 & 3,080 & 595 & 2,256 \\
Frijol & 450 & 450 & 115 & 369 \\
Cilantro & 22 & 22 & 33 & 41 \\
Coliflor & 20 & 20 & 20 & 20 \\
Haba verde & 20 & 20 & 70 & 73 \\
Chile verde & 20 & 20 & 30 & 29 \\
Avena forrajera & 15 & 15 & - & 62 \\
Chícharo & 15 & 15 & 60 & 62 \\
Col (Repollo) & 15 & 15 & 15 & 15 \\
Maíz forrajero & 0 & 10 & 10 & 10 \\
Espinaca & 7 & 9 & 100 & 80 \\
Tomate verde & 6 & 6 & - & 4 \\
Cebolla & 5 & 5 & 5 & 31 \\
Cebada forrajera & 5 & 5 & 5 & 37 \\
Col de bruselas & 5 & 5 & 5 & 5 \\
Calabacita & 2 & 2 & 2 & 2 \\
Nabo forrajero & 2 & - & - & - \\
Gladiola (gruesa) & - & - & 10 & 9 \\
Total & 3,699 & 3,699 & 1,075 & 3,105 \\
\hline Fuente: elaboración propia a partir de datos del Servicio de Información Agroalimentaria y \\
pesquera (SIAP, 2015).
\end{tabular}


Una mayor articulación de la producción campesina en el mercado genera la disminución de la producción de granos básicos que se orientan al autoconsumo (Ramírez y Méndez, 2007). Los datos de la Tabla 7, indican que solo en 1990 se sembró nabo forrajero y a partir del 2010 en adelante se comienza a sembrar gladiola; los cultivos que se vuelven más representativos para 2015 son la espinaca, que mientras en el 1990 solo representaba 0.2 por ciento del total de la superficie sembrada, en 2015 representa tres por ciento, así también la cebolla que pasa de 0.1 a uno por ciento, la cebada forrajera de 0.1 a 1.2 por ciento, la avena 0.4 a dos por ciento y el chícharo que pasan de 0.4 a dos por ciento. Esta transformación de la estructura de cultivos no implica el cambio y sustitución completa de la vieja estructura orientada a la producción de maíz, más bien se van entretejiendo los cultivos.

Las familias del municipio estudiado, realizan cambios en la producción de cultivos orientados por los precios de mercado, de manera que se puedan obtener los máximos beneficios de esta relación. Así, en la Tabla 8 se presentan los cultivos perennes en Calpan, y se considera que los cultivos menos rentables económicamente como el tejocote, la manzana o el durazno, han disminuido su producción; y se aumentó la producción de cultivos que las familias consideran más rentables, porque mencionaron que necesitan menores insumos para su producción y de los cuales obtienen mayores ventajas económicas.

Tabla 8: Superficie sembrada en hectáreas de cultivos perennes y valor de la producción en miles de pesos del municipio de Calpan, 1990-2015

\begin{tabular}{lrrrr}
\hline & \multicolumn{3}{c}{2015} \\
\hline Cultivo & $\begin{array}{r}\text { Superficie } \\
\text { Sembrada/Ha }\end{array}$ & $\begin{array}{r}\text { Valor } \\
\text { Producción }\end{array}$ & $\begin{array}{r}\text { Superficie } \\
\text { Sembrada/Ha }\end{array}$ & $\begin{array}{r}\text { Valor } \\
\text { Producción }\end{array}$ \\
\hline Alfalfa verde & 23 & 462.07 & 35 & $1,277.51$ \\
Ciruela & 6 & 75.6 & 18 & 590.52 \\
Durazno & 22 & 770 & 7 & 262.5 \\
Manzana & 73 & $1,578.80$ & 46 & $1,229.50$ \\
Pera & 63 & 423 & 73 & $1,563.60$ \\
Tejocote & 90 & $1,957.20$ & 86 & 795.06 \\
Total & 277 & $5,266.67$ & 265 & $5,718.69$ \\
\hline
\end{tabular}

Fuente: elaboración propia a partir de datos del SIAP, 2015. 
Es de considerar que con la finalidad de incrementar el beneficio de los árboles frutales en Calpan, se realiza la feria del chile en nogada ${ }^{10}$ del 8 al 17 de agosto; además del 15 al 16 de noviembre se realiza también la feria del tejocote, dichas actividades están cobrando importancia en la zona y de la cual muchas familias dependen. Las entrevistas semiestructuradas a informantes clave, permitieron entender que en el municipio de Calpan la identidad de los habitantes se sustenta a través del cultivo de la milpa y la siembra de árboles frutales, ambos relacionados con la preparación de alimentos (el chile en nogada, el pulque, las tortillas de maíz hechas a mano, el mole, etc.); al respecto Iturriaga considera que:

La comida mexicana es una matriz de antiguos conocimientos enriquecidos en diferentes etapas de mestizaje, que subsisten en la actualidad en los surcos y en las milpas, en las cocinas y en las mesas, también de alguna manera en templos y cementerios, en cunas y altares, en rezos y costumbres del pueblo, sea indígena o no. Nuestra cocina es un conjunto cultural que deviene eje de usos y prácticas comunitarias y familiares. La cocina mexicana es un factor de cohesión social y uno de los más poderosos elementos de la identidad nacional (Iturriaga, 1946: 1).

\section{Transformaciones del uso del suelo}

Al analizar los espacios no podemos separar los sistemas, los objetos y las acciones que se complementan con el movimiento de la vida, en el cual las relaciones sociales producen los espacios y los espacios, a su vez, las relaciones sociales. Este movimiento continuo es un proceso de producción de territorios (Mançano, 2009). Para Ramírez y Méndez (2007), es a partir de la distribución y tenencia de la tierra y el uso del suelo lo que constituye la base del sistema agrario, que al interaccionar con el sistema biofísico, económico, técnico y social establece los sistemas de cultivo. El estudio de su evolución permitirá identificar las transformaciones en el territorio estudiado.

En 1992 en México, concluye el reparto agrario con la modificación del Artículo 27 constitucional y la publicación de la Ley Agraria; aquí inicia una nueva etapa, la del ordenamiento de la propiedad social, y además, la actualización del catastro rural y la atención de conflictos agrarios (Cedrún, 2011). Lo anterior desmantela el carácter exclusivo, inembargable

\footnotetext{
${ }^{10}$ El chile en nogada es uno de los platillos típicos de la gastronomía mexicana, más concretamente del estado de Puebla. Se prepara con chile poblano relleno de un guisado de picadillo y frutas, cubierto con crema de nuez (blanco), perejil (verde) y granada (rojo), con lo cual se simbolizan los tres colores de la bandera de México.
} 
y perdurable de la propiedad ejidal al abrir las vías para el comercio de tierras.

Datos del Censo Ejidal de 1990 y de 2015, indican que en Calpan, la propiedad privada en 1990 era de 67 por ciento, mientras que la ejidal y comunal representaban 26 por ciento y solo siete por ciento era pública. Para 2015 la propiedad privada pasa a representar 81 por ciento, la ejidal y comunal 18.5 por ciento y 0.5 por ciento la pública. Como se observa la propiedad privada ha aumentado 14 por ciento. En relación a la superficie total de las unidades de producción agropecuaria para 2015, registraron 7,296.83 hectáreas, de las cuales según el tipo de derechos sobre la tierra, 86 por ciento es propia, uno por ciento rentada, nueve por ciento a medias o en aparcería y cuatro por ciento entre prestada y otros.

En la Figura 3 se observa que los asentamientos humanos han aumentado y se ha reducido el área de cultivo. Particularmente en la Tabla 9 se especifican las ganancias y pérdidas en el uso del suelo. Calpan, muestra una dispersión poblacional alejada de la cabecera municipal. Las causas de esa dispersión poblacional hacia nuevas localidades más alejadas de la cabecera municipal, se podrían explicar por diferentes factores que interactúan de forma conjunta, se fortalecen unos a otros y resultan difíciles de individualizar y acotar (Kontuly, 1998; Gkartzios y Scott, 2010; Cadieux, 2008). Torres (2014), precisa que en estos nuevos patrones de dispersión geográfica influyen causas macroeconómicas, tales como los ciclos de crecimiento económico o los efectos desencadenados por la globalización, también factores microeconómicos, demográficos, psicosociales relacionados con cambios en las preferencias residenciales, transformaciones técnicas vinculados a la mejora de las condiciones de trasporte y de la accesibilidad, entre otros.

Concretamente en la Figura 4, se observa que los asentamientos humanos y su distribución municipal, se dirigen hacia el municipio de Huejotzingo. Hasta 2010 la población había dirigido su dispersión hacia San Mateo Ozolco, más cerca del volcán y del municipio de San Nicolás de los Ranchos; sin embargo para 2014 las localidades de reciente crecimiento como Pueblo Nuevo y el Palmar, se están dirigiendo hacia Huejotzingo, donde la economía se sustenta en el sector secundario y terciario (INEGI, 2015a), y los habitantes de Calpan buscan insertarse laboralmente en esos sectores. 
Figura 3: Cambio del uso del suelo en el municipio de Calpan de 1990-2015

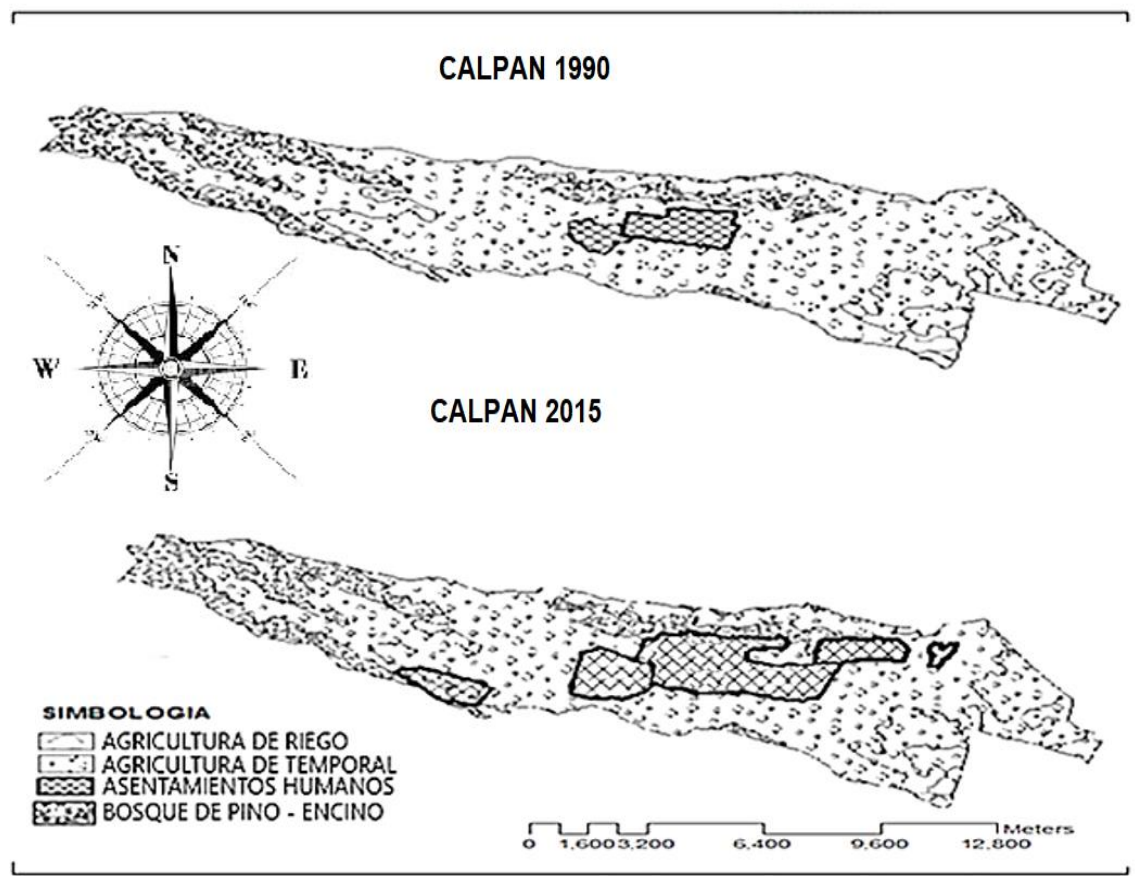

Fuente: elaboración propia con datos de cartografia de INEGI, 2015c.

Tabla 9: Ganancias y pérdidas en el uso del suelo en el periodo 1990-2015

\begin{tabular}{lrr}
\hline Tipo & $\begin{array}{r}\text { Porcentaje } \\
\text { Incremento-Decremento }\end{array}$ & $\begin{array}{r}\text { Superficie (hectáreas) } \\
\text { Incremento-Decremento }\end{array}$ \\
\hline Agricultura de temporal & $-5 \%$ & -792.1 \\
Agricultura de riego & $+2 \%$ & +101.2 \\
Bosque de pino-encino & $-4 \%$ & -248.2 \\
Asentamientos humanos & $+18 \%$ & +1028.3 \\
\hline
\end{tabular}

Fuente: elaboración propia con datos del INEGI, 2015b. 
Transformaciones territoriales y estrategias de superviviencia: el caso del municipio ... /J.L. LÓPEZ GONZÁLEZ et al.

Figura 4: Asentamientos Humanos en Calpan, Puebla-México 2015

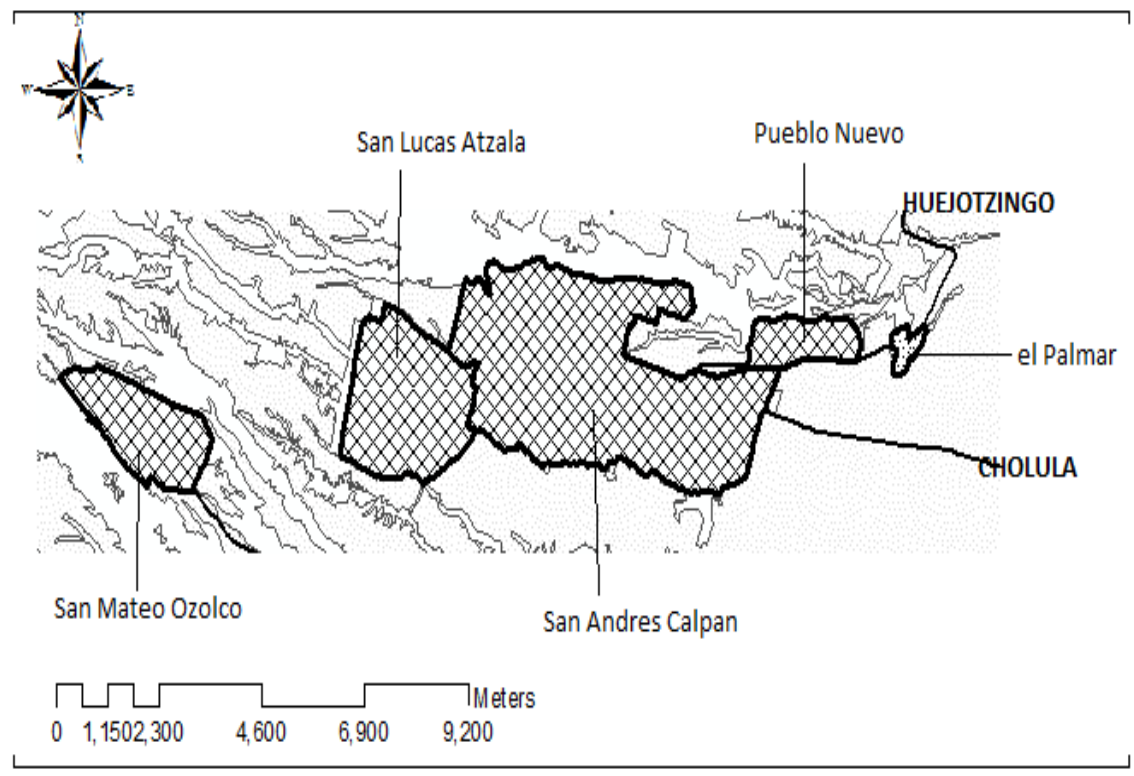

Fuente: elaboración propia con datos de cartografia de INEGI, 2015c.

De esta forma, la desconcentración de la población en el municipio se estaría desplazando por factores económicos estructurales, ya que la desconcentración del empleo y de las actividades económicas, junto con la nueva división espacial del trabajo, hacen que la organización espacial de la producción presente patrones más desconcentrados que en el pasado (Cloke, 1985; Fielding, 1998).

\section{Conclusiones}

La indagación histórica indica que la presencia española en el territorio no solo modificó las prácticas en la agricultura con la incorporación de nuevos cultivos, prácticas y herramientas, sino que modificaron el espacio ocupado por el municipio debido a la incorporación de animales de pastoreo, así como animales de tiro utilizados en actividades agrícolas.

El análisis revela un incremento poblacional y un acelerado proceso de urbanización en los últimos 25 años. Sin embargo los indicadores sociales señalan que Calpan se encuentra inmerso en una profunda desigualdad de 
oportunidades de participación en el proceso de desarrollo y de disfrute de sus beneficios.

En cuanto a la estructura socioeconómica en el municipio, se observó que la agricultura de tiempo parcial es una realidad, ya que se complementa con trabajos de albañilería, plomería, panadería, choferes de taxi, jornaleros, entre otros. Y es que el nuevo orden agrícola internacional no solo influye en la diversificación de actividades, sino también en las tendencias de cambio y recomposición de la producción agrícola en el municipio de Calpan.

Esto ha transformado al territorio y modificado las estrategias de supervivencia de los habitantes, ya que mientras en 1990 gran parte de la población se dedicaba al sector primario, actualmente la tendencia muestra que esta actividad está siendo desplazada por el sector terciario de la economía; asimismo, el análisis espacial muestra que en 1990 la población se orientaba a zonas agrícolas más cercanas al volcán, sin embargo en el periodo de 2010 a 2015 se muestra una creciente urbanización hacia las cercanías de otros municipios. Lo que indica que los habitantes se desplazan a espacios donde puedan ofertar su fuerza de trabajo e incorporarse al sector económico terciario.

\section{REFERENCIAS BIBLIOGRÁFICAS}

Acosta, E. Z. y Pérez, M. A. M., 2004, Inventario del archivo parroquial San Andrés Apóstol. Arzobispado de Puebla Calpan, México. Apoyo al desarrollo de archivos y bibliotecas de México. Puebla, México. 24 p.

Anseeuw, W. and Laurent, C., 2007, "Occupational paths towards commercial agriculture: The key roles of farm", in Journal of Arid Environments. vol. 70. núm. 4: 659-671.

Barkin, D., 1991, Un desarrollo distorsionado: la integración de México a la economía mundial, Siglo XXI, México. 207 p.

Bourdieu, P., 2011, Las estrategias de la reproducción social. Siglo XXI editores. Buenos Aires, Argentina. 224 p.

Bustamante, J., Guillermina, J. E., Taylor, J. and Paz, T. L., 1998, “Características of migrantes: Mexicans in the United States, Migration between México and the United States: Binational Study, Austin Texas. US”, in Morgan printing, vol. 11. núm. 1: 91-162.

Cadieux K.V., 2008, "Political ecology of exurban life style land scapes at Christchurch's contested urban fence", in Urban Forestry and Urban Greening. vol. 7. núm. 3: 183-194. 
Calva, J. L., 1992, "El modelo de desarrollo agropecuario impulsado mediante la Ley Agraria y el TLC”, en Calva, Jose Luis (coord.), Alternativas para el campo mexicano. Fontanamara, Pual-UNAM/Fundación Friedrich Ebert, México. 156 p.

Castellanos, O. N. M., 2014, Arquitectura de tierra: patrimonio y sustentabilidad en regiones sísmicas, en $14^{\circ}$ Siacot, Seminario Iberoamericano de Arquitectura y Construcción con Tierra (SIACOT). San Salvador, El Salvador. 261 p.

Cedrún, V. J. M. E., 2011, “El catastro rural en México," en Revista Estudios Agrarios, vol. 2, núm 3: 37-48.

Cloke, P., 1985, "Counter urbanisation: a rural perspective", in Geography. vol. 17. núm. 70: 13-29.

CONAPO, 2010, Índices de Marginación, Consejo Nacional de Población, México. Disponible en http://www.conapo.gob.mx/ work/models/CONAPO/indices margina/indices/pdfs/ IM2000_docprincipal.pdf

CONAPO, 2011, Dinámica Demográfica de la Población Joven de México. Consejo Nacional de Población Disponible en http://www.conapo.gob.mx/publicaciones/juventud/capitulos/01.pdf.

CONEVAL, 2014, Líneas de bienestar y canasta básica. Comité Nacional de Evaluación de la Política Social, Disponible en http:/www. coneval.gob.mx/Medicion/Paginas/Lineas-de-bienestar-ycanasta-basica.aspx

CONEVAL, 2015, Medición de niveles de pobreza por municipio. Comité Nacional de Evaluación de la Política Social Disponible en http://www.coneval.gob.mx/ Medicion/Paginas/Medición/ Tablas-dinamicas-municipales.aspx.

Damián, H. M. A., Ramírez, B., Gil ,A. N. Gutiérrez, A., Aragón, R., Mendoza, J. C., Paredes, T. D., y Almazán, A., 2004, Apropiación de tecnología agrícola. Características técnicas y sociales de los productores de maíz de Tlaxcala. Puebla, Benemérita Universidad Autónoma de Puebla, CONACYT-SIZA y H. Congreso del estado de Tlaxcala. Puebla, México. 296 p.

Duque, J. y Pastrana, E., 1973, Las estrategias de supervivencia de las unidades familiares del sector popular urbano. ELAS/CELADE. Santiago de Chile. 123 p.

Echanove, F. y Steffen, C., 2005, Globalización y reestructuración en el agro mexicano. Los pequeños productores de cultivos no tradicionales. Universidad Autónoma Chapingo, Plaza y Valdés. México. 67 p.

Fielding, A. J., 1998, "Counterurbanisation and social class", in Boyle, P.; Halfacree, K. (eds.): Migration into Rural Areas. Theories and issues. Wiley, Chichester, pp. 41-60. Disponible en http://www.tandfonline.com/doi/ abs/10.1080/00369220218737133

Galindo A., 1994, "La agricultura de tiempo parcial en los países industrializados: el caso de Italia”, en Comercio Exterior, vol. 4. núm. 44: 313-320.

Gkartzios, M. y Scott, M., 2010, "Residential mobilities and house building in rural Ireland: evidence from three case studies", in Sociologia Ruralis. vol. 50. núm. 1: 64-84. 
Gorenstein, S., 2015, “Transformaciones territoriales contemporáneas. Desafíos del pensamiento latinoamericano, en EURE. vol. 41. núm. 122: 5-26.

Granados, R. G., 1935, “Capillas de indios en Nueva España (1530-1605)”, en Archivo español de arte y arqueología, vol. 11. núm. 31: 3-19.

Grammont de, H. C., 2016, "Hacia una ruralidad fragmentada: La desagrarización del campo mexicano", en Nueva Sociedad, vol. 15. núm. 262: 51-63.

Grammont de, H., 2006, La nueva estructura ocupacional en los hogares rurales mexicanos: de la Unidad Económica Campesina a la Unidad Familiar Pluriactiva. ALASRU, (CD-ROM). Quito, Ecuador. 41 p.

Hausmann, R., and Klinger, B., 2008, Examining beneficiation, Center for International Development at Harvard University.

Hintze, S., 1989, "Estrategias alimentarias de sobrevivencia. Un estudio de caso en el Gran Buenos Aires", en Centro Editor de América Latina. vol. 2. núm. 5: 21-45.

INAFED, 2010, Enciclopedia de los municipios y delegaciones de México. Estado de Puebla. Instituto Nacional del Federalismo, Disponible en http://www.elocal. gob.mx/work/templates/enciclo/ EMM21puebla/municipios/21026/

INEGI, 2000, XII Censo general de población y vivienda 2000. Instituto Nacional de Estadística Geografía e Informática, Disponible en http:// operativos.inegi.org. $\mathrm{mx} /$ sistemas/iter/entidad_indicador/

INEGI, 2010, Prontuario de información geográfica municipal de los Estados Unidos Mexicanos: Calpan, Puebla. Instituto Nacional de Estadística Geografía e Informática, Disponible en http://mapserver. inegi.org.mx/dsist/prontuario/index2.cfm.

INEGI, 2015a, Encuesta Intercensal 2015. Instituto Nacional de Estadística Geografía e Informática, Disponible en http://operativos.inegi. org.mx/sistemas/iter/ entidad/

INEGI, 2015b, México en cifras. Información nacional, por entidad federativa y municipios. Instituto Nacional de Estadística Geografía e Informática, Disponible en http://www3.inegi.org.mx/sistemas/mexicocifras/default.aspx?e=21

INEGI, 2015c, Cartografía del estado de Puebla, México. Instituto Nacional de Estadística Geografía e Informática, Disponible en http://www.inegi.org.mx/geo/ contenidos/urbana/defa/

INEGI, 1990, Anuario Estadístico del Estado de Puebla. Tomo II, Instituto Nacional de Estadística Geografía e Informática México, 456 p.

Iturriaga, J. N., 1946, "La identidad alimentaria mexicana como fenómeno cultural”, en Archipiélago. Revista cultural de nuestra América. vol. 14. núm. 56: $35-51$.

Janvry de, A. y Sadoulet, E., 2004, "Estrategias de ingresos de los hogares rurales de México: el papel de las actividades desarrolladas fuera del predio agrícola", en Reardon, T. et al., Empleo e ingresos rurales no agrícolas en América Latina. 
Comisión Económica para América Latina (CEPAL), Serie Seminarios y Conferencias, núm. 35:107-127Santiago de Chile.

Jiménez, M. F. A., 2008, "La seguridad alimentaria: una estrategia para el desarrollo rural del estado de Puebla", en Jiménez Merino, F. Alberto (coord.) Seguridad alimentaria en Puebla: importancia, estrategias y experiencias. Puebla. Secretaría de Desarrollo Rural, Colegio de Postgraduados Campus Puebla. México. 221 p.

Kontuly, T., 1998, "Contrasting the counterurbanisation experience in European nations", in Boyle, P.; Halfacree, K. (eds.): Migration into Rural Areas. Theories and issues. Wiley, Chichester. Estados Unidos. 78 p.

Llambi, L. y Pérez, E. C., 2007, "Nuevas ruralidades y viejos campesinismos: agenda para una nueva sociología rural latinoamericana", en Cuadernos de Desarrollo Rural, Bogotá. vol. 4. núm. 59: 37-61.

Lomnitz, L. A., 1975, Cómo sobreviven los marginados. Siglo XXI, México. 120 p.

López, P. S., 2009, Diagnostico sociodemográfico de la megapolis del centro del país, Universidad Autónoma del Estado de Hidalgo, Pachuca, México, 2008. 98 p.

Mançano, F. B., 2009, “Territorio, teoría y política”, en Lozano Velázquez, Fabio y Ferro Medina, Juan Guillermo (editores), Las configuraciones de los territorios rurales en el siglo XXI. Editorial Pontificia Universidad Javeriana. Bogotá, Colombia. $62 \mathrm{p}$.

Méndez, E. J. A., Tomé, H. G., Pérez, R. N., and Ramírez, J. J., 2017, “Transformaciones socioeconómicas territoriales en el municipio de San Martín Texmelucan, México 1980-2010", en Nova Scientia, vol. 9. núm. 18.

Meraz, Q., 2006, Urbanismo indígena y español en el México del siglo XVI: el caso de Calpan. Tesis Doctorado en Diseño, Universidad Autónoma Metropolitana, Unidad Azcapotzalco, División de Ciencias y Artes para el Diseño. México. $336 \mathrm{p}$.

Meraz, Q. y Guerrero, B. L., 2011, “Calpan (México), historia, urbanismo y tapial", en Construcción con tierra. Tecnología y Arquitectura. Congresos de arquitectura de tierra en cuenca de campos 2010|2011. Valladolid: Catedra Juan de Villanueva. Universidad de Valladolid. España. 46 p.

Peláez,H. O., 2012, “Análisis de los indicadores de desarrollo humano, marginación, rezago social y pobreza en los municipios de Chiapas a partir de una perspectiva demográfica", en Economía Sociedad y Territorio. vol. 12. núm. 38: 181-213.

Pérez ,E., 2001, "Hacia una nueva visión de lo rural", en Una nueva ruralidad en América Latina. vol. 3. núm. 2: 17-29.

Plaza, O., 2002, "Perspectivas y enfoques de desarrollo rural: visión desde América Latina", en Políticas, instrumentos y experiencias de desarrollo rural en América Latina y Europa. Centro de Publicaciones Agrarias, Pesqueras y Alimentarias. México. Pp. 33-46. 
Ramírez, J. J. y Méndez, E. J. A., 2007, Transformaciones agrarias y estrategias de reproducción campesina en el Soconusco, Chiapas, Colegio de Postgraduados en Ciencias Agrícolas, campus Puebla, Fondo Mixto de Fomento a la Investigación, Científica y Tecnológica CONACYT- Gobierno del Estado de Chiapas, México. $158 \mathrm{p}$.

Rubio, B., 2006, "Territorio y globalización en México: ¿un nuevo paradigma rural?", en Comercio Exterior. vol. 56. núm. 12: 1047-1054.

Sacco, D. A. F y Velleda, N. C., 2007, Pluriactividad y agricultura familiar en Brasil: el caso de Río Grande do Sul”, en Revista de la CEPAL 93, diciembre. vol. 16. núm. 34: 157-173.

SIAP, 2015, Servicio de Información Agroalimentaria y Pesquera. Disponible en www.siap.gob.mx/

Tapia, G. J. A., 1995, Algunas ideas críticas sobre el índice de desarrollo humano. Oficina Sanit Panam. Bolivia. 119 p.

Torres, E. R., 2014, La dispersión urbana en el país Vasco. Los patrones de la redistribución espacial de la población y nuevas realidades residenciales y urbanísticas, 1991-2010. Universidad del país Vasco. Tesis doctoral geografía prehistoria y arqueología, Universidad de Arte y Humanidades. España. 251 p.

Torres, F., 2009, "Un marco de referencia para comparar los procesos regionales", en Formaciones Regionales Comparadas: los casos de México, España e Italia. El colegio de Tlaxcala, A.C, UNAM, Instituto de investigaciones económicas. México. 49 p.

Velásquez, M. E. S., 2012, Cómo entender el territorio?. Editorial Cara Parens, Universidad Rafael Landívar. 146 p.

Villa I. M., 2008, ¿Qué hacemos con el campo mexicano? Editorial Mundi P. México. $231 \mathrm{p}$.

Virve, P., 1981, La secularización de las parroquias en la nueva España y su repercusión en San Andrés Calpan, México. Instituto Nacional de Antropología e Historia (INAH), México. 195 p.

\section{RESUMEN CURRICULAR DE LOS AUTORES}

\section{José Luis López González}

Licenciado en Economía por la Benemérita Universidad Autónoma de Puebla, Maestro y Doctor en Ciencias en el Programa Estrategias para el Desarrollo Agrícola Regional en el Colegio de Postgraduados Campus Puebla. Ha realizado estancias de investigación en Colombia y España. Colegio de Postgraduados, Campus Puebla. Boulevard Forjadores de Puebla No. 205, Santiago Momoxpan, Municipio San Pedro Cholula. C.P. 72760, Puebla, México.

Dirección electrónica: luistric_17@hotmail.com 


\section{José Arturo Méndez Espinoza}

Doctor en Geografía, con especialidad en Planificación Territorial y Desarrollo Regional. Universidad de Barcelona, España; Profesor Investigador Titular SNI I del Colegio de Postgraduados, Campus Puebla. Boulevard Forjadores de Puebla No. 205, Santiago Momoxpan, Municipio San Pedro Cholula. C.P. 72760, Puebla, México.

Dirección electrónica: jamendez@colpos.mx

\section{Susana Edith Rappo Miguez}

Doctora en Economía por la Universidad Nacional Autónoma de México (UNAM). Profesora Investigadora titular "B" de tiempo completo, Facultad de Economía y del Centro de Investigación y Estudios de Postgrado (CIEPE), de la Benemérita Universidad Autónoma de Puebla (BUAP).

Dirección electrónica: susanarappo@hotmail.com

\section{Miguel Ángel Damián Huato}

Doctor en Ciencias por el Colegio de Postgraduados. Profesor Investigador Titular SNI II de la Benemerita Universidad Autonoma de Puebla en el Centro de Agroecología del ICUAP, ubicado en 14 Sur 6301, colonia San Manuel en Ciudad Universitaria.

Dirección electrónica: damianhuato@hotmail.com

\section{Jesús Felipe Álvarez Gaxiola}

Doctor por el Instituto de Estudios Campesinos de Córdoba, España. Profesor Investigador Titular del Colegio de Postgraduados, Campus Puebla. Boulevard Forjadores de Puebla No. 205, Santiago Momoxpan, Municipio San Pedro Cholula. C.P. 72760, Puebla, México.

Dirección electrónica: felipe_alvarez@hotmail.com

\section{Juan Alberto Paredes Sánchez}

Doctor por la Universidad Complutense de Madrid, España. Profesor Investigador Titular del Colegio de Postgraduados, Campus Puebla. Boulevard Forjadores de Puebla No. 205, Santiago Momoxpan, Municipio San Pedro Cholula. C.P. 72760, Puebla, México.

Dirección electrónica: paredes52@colpos.mx 